\title{
An Electron Microscope Study of Spinal and Rubral Fiber- Recipient Regions in the Inferior Olive of the Cat
}

\author{
By \\ Noboru MIZUNo, Akira KONISHI*, Yasuhisa NAKAMURA**, \\ YUKIHIKo YASUI and NobUhaRU IWAHORI*** \\ Department of Anatomy (1st Division), Faculty of Medicine, and College \\ of Medical Technology*, Kyoto University, Japan \\ - Received for Publication, September 16, 1981-
}

Key words: Inferior olive, Spino-olivary fibers, Rubro-olivary fibers, Electron microscope, Cat.

Summary: Synaptic organization in the spinal and rubral fiber-recipient regions in the inferior olive (IO) of the cat was examined electron microscopically; the spinal fiber-recipient regions were the caudolateral portions of the medial accessory olive (MAO) and the lateral portions of the dorsal accessory olive (DAO), and the rubral fiber-recipient regions were the middle portions of the dorsal lamella of the principal olive (PO).

The density of axosomatic (AS) synaptic terminals (the number of AS terminals per $100 \mu \mathrm{m}$ length of somatic membrane) was calculated on each somatic profiles cut through the nuclear plane. It ranged from 0 to 12.0 with an average of $2.4 \pm$ 0.32. No correlations were recognized between the cell size and the density of AS terminals. About $25 \%$ of AS terminals were filled with round synaptic vesicles (Rtype), and 75\% contained pleomorphic synaptic vesicles (P-type). About 60\% axodendritic $(\mathrm{AD})$ axon terminals were of $\mathrm{R}$-type, and $40 \%$ were of $\mathrm{P}$-type.

In the cats allowed to survive for 2 to 7 days after hemicordotomy at the 2nd cervical cord segment, or after placing lesions in the red nuclear regions, electrondense axon terminals were seen ipsilaterally in the MAO and DAO regions, or in the $P O$ regions, respectively. The vast majority of these degenerated axon terminals were in contact with dendritic profiles and appeared to be of R-type. Although electron-dense axon terminals never exceeded more than $7 \%$ of the total population of axon terminals in the 10 regions examined, the ratio of AD terminals of R-type to those of P-type was decreased in the $I 0$ regions deafferented from spinal or mesencephalic fibers for 35 days.

\footnotetext{
** Present address : Department of Anatomy (3rd Division), Faculty of Medicine, Kanazawa University.

*** Present address: Department of Anatomy (1st Division), Faculty of Medicine, Nagasaki University.
} 
The inferior olive (IO) has been well known as a major precerebellar nucleus receiving afferent fibers from a wide variety of sources in the central nervous system (for reviews, cf. Armstrong, '74; Courville et al., '80). Among afferent fibers terminating within district IO regions of the cat, spinal and rubral fibers are numerous (Brodal et al., '50; Walberg, '56; Mizuno, '66 ; Edwards, '72 ; Boesten and Voogd, '75; Berkley and Worden, '78). Although a number of electron microscopic studies have been done on the IO in the opossum (Bowman and King, '73; King et al., '75, .76, '78; King, '76), rat (Gwyn, '77), rabbit (Mizuno et al '74), cat (Walberg, '63, '66; Němeček and Wolff, '69; Sotelo et al., '74), and squirrel monkey (Rutherford and Gwyn, '77, '80), findings on the mode of termination of afferent fibers to the IO in the cat have been described rather sporadically (Walberg, '64, '65, '71; Alksne et al., '66; Mizuno et al., '76, '80a, '80b).

In view of these circumstances, the present study was performed primarily in an attempt to analyse quantitatively synaptic terminals of the spino- and rubroolivary fibers in the IO of the cat. Some of the findings reported in this communication were the subject of the previous report (Mizuno et al., '76, '80a).

\section{Material and Methods}

Experiments were performed on 29 adult cats of either sex, ranging in weight from $2.0 \mathrm{~kg}$ to $5.0 \mathrm{~kg}$. Twenty-two of them were subjected to surgical or electrolytic lesions under general anesthesia (sodium pentobarbital, $35-40 \mathrm{mg} / \mathrm{kg}$ i.p.) ; hemicordotomy in the 2 nd cervical cord segment was made on 12 cats, and electrolytic lesions were placed stereotaxically in the red nuclear regions of the midbrain in 10 cats. All of these cats were treated postoperatively with penicillin, and allow- ed to survive for a period of 2 to 35 days before being again anesthetized and perfused. The remaining 7 cats were served for controls.

The cats, which were anesthetized with an overdose. of pentobarbital, were perfused intravitally through the ascending aorta with 1.5 to 2 liters of a mixture composed of $4 \%$ paraformaldehyde, $0.5 \%$ glutaraldehyde, and $0.002 \%$ calcium chloride in Millonig's phosphate buffer adjusted to $\mathrm{pH}$ 7.3. Perfusion was extended over a period of 15 minutes from a height of about $1 \mathrm{~m}$. After perfusion, the brain and cervical cord segments were removed, and blocks which included the IO were cut transversely at $150 \mu \mathrm{m}$ thickness on a Vibratome (Oxford Laborratories. Foster City. California); the sections were floated on a bath of the perfusion fixative. Subsequently, small tissue slices containing the IO were prepared with fresh razor blades under a dissecting microscope, and postfixed for 40 to 60 minutes in a chilled $2 \%$ solution of osmium tetroxide in the same buffer used for preparing the perfusion fixative. Embedding was performed in an epoxy resin after dehydration in a graded series of ethanol. The location of the IO regions was again verified in semithin sections, which were cut from each block and stained with $0.5 \%$ toluidine blue in $1 \%$ borax. The block face was then trimmed to include only the required IO regions (caudolateral portions of the MAO, lateral portions of the DAO, or middle portions of the $\mathrm{PO}$ ) so that ultrathin sections could be made. Thin sections for electron microscopy were cut on an LKB Ultratome III 8800 or a Porter-Blum Ultra-microtome MT-1, stained on uncoated or collodion-coated copper grid with lead acetate (Millonig, '61) or lead citrate (Venable and Coggeshall, '65), and viewed with a Hitachi HU-12 electron microscope. The location and extent of 
the lesion in each of the operated cats were verified histologically as described elsewhere (Mizuno et al., '75).

Quantitative analysis of axon terminals was attempted: In the central parts of each grid hole (120-130 $\mu \mathrm{m}$ diameter), 21 rectangular fields $\left(21 \times 67.4 \mu \mathrm{m}^{2}\right)$ of the neuropil were photographed serially without reference to their contents at an initial magnification of $\times 10,000$, and subsequently enlarged on paper to a final magnification of $\times 25,000$. On these prints, both axosomatic (AS) and axodendritic (AD) axon terminals were categorized into terminals with round synaptic vesicles (R-type) and those with pleomorphic ones (P-type: mixture of varying ratios of round and elongated synaptic vesicles), and the numbers of the two types of axon terminals were counted.

The density of AS terminals (the number of axon terminals with synaptic active zones per $100 \mu \mathrm{m}$ length of the cell membrane on each somatic profile) was calculated: Somatic profiles of nerve cells cut through the nuclear plane were sampled randomly, and the number of AS terminals upon these somatic profiles were counted through direct inspection of the actual section at high magnification $(\times 20,000$ to $\times 30,000)$. Subsequently, these somatic profiles were photographed with a magnification of $\times 2,000$ to $\times 5,000$. The sheet film $(8 \times 9 \mathrm{~cm})$ were printed to a final magnification of $\times 5,000$ to $\times 20$,000 . Some of these prints were taped together to form montages of neuronal somata. On these prints or montages the length of the membrane of the soma was measured with an odometer. The longest and shortest diameters of each somatic profiles were cut through the nucleolar plane were also measured, and the mean of these values was recorded.

\section{Results}

The spino-olivary fibers terminate mainly in the caudolateral portions of the medial accessory olive (MAO) and the lateral portions of the dorsal accessory olive (DAO) (Brodal et al., '50; Mizuno, '66; Boesten and Voogd, '75; Berkley and Worden, '78). On the other hand, the rubro-olivary fibers end chiefly in the dorsal lamella of the principal olive (PO) (Walberg, '56; Edwards, '72). Since the present study was primarily attempted to examine the mode of termination of spino- and rubro-olivary fibers, electron microscopic examination was performed in the spinal and rubral fiber-recipient IO regions.

\section{Findings in unoperated cats}

Most of the ultrastructural characteristics reported previously in the $\mathrm{IO}$ of the cat (Sotelo et al., '74) were substantiated in the present study. The frequent occurrence of the intranuclear inclusions (Plate 1A, 1B) and the casual apposition between a soma and a dendrite (Plate $2 \mathrm{~A}$ ), between neuronal somata (Plate $2 \mathrm{~B}$ ), and between crossing dendrites (Plate 2C) were confirmed. On rare occasions, somatic spines, the gap junctions between dendrites (Plate 2C), and perikaryal myelin (Plate 3A) were also observed. Of 93 intranuclear inclusions identified in the present study, 11 were of the lattice type (Chandler and Willis, '66; Feldman and Peters, '72) (Plate 1A) and 82 were of the rodlet type (Siegesmund et al., '64; Feldman and Peters, '72) (Plate 1B).

The association between the shape of synaptic vesicles and the type of synaptic active zones was not consistent; most of axosomatic (AS) terminals and the vast majority of axodenritic (AD) terminals containing pleomorphic synaptic vesicles (AD terminals of P-type) were associated 
with the symmetrical active zones, whereas AD terminals filled with round synaptic vesicles ( $A D$ terminals of R-type) were usually associated with the asymmetrical zones of the synapses (Plate 3B, $3 C)$. Several $A D$ terminals were often arranged in a glomerular manner (Plate $3 \mathrm{C}$ ), as described previously (Němeček and Wolff, '69; Sotelo et al., '74). AD terminals of the en passent type, and axon terminals protruding directly from a myelinated portion of axon or a node of Ranvier rarely observed (Plate 3D), but no axo-axonal synapses were found.

The density of AS synaptic terminals (the number of AS terminals with synaptic active zones per $100 \mu \mathrm{m}$ length of the cell membrane) was calculated on each of somatic profiles cut through the nuclear plane; the density ranged from 0 to 12.0 with an average of $2.4 \pm 0.32$ (147 profiles) (Table 1). For each of 100 somatic profiles cut through the nucleolar plane, the largest and smallest diameters were measured. The mean of these values ranged from $13.1 \mu \mathrm{m}$ to $28.7 \mu \mathrm{m}$ with an average of $18.1 \mu \mathrm{m}$ in the MAO (36 profiles), from $13.4 \mu \mathrm{m}$ to $27.9 \mu \mathrm{m}$ with an average of $17.5 \mu \mathrm{m}$ in the DAO (34 profiles), and from $13.8 \mu \mathrm{m}$ to $23.0 \mu \mathrm{m}$ with an average of $18.3 \mu \mathrm{m}$ in the $\mathrm{PO}$ (30 profiles). An analysis made on these 100 somatic profiles cut through the nucleolar plane showed that no clear correlations existed between the cell size and the density of AS terminals (Plate 1C).
The terminals of R-type were seen in $25.0 \pm 1.62 \%$ of the AS terminals (180 out of 718 AS terminals counted), and in $61.1 \pm 0.62 \%$ of the $\mathrm{AD}$ terminals (3728 out of 6097 AD terminals counted) (Table 2). The ratio of the two types of either AS or AD terminals was not different significantly among the MAO, DAO and PO, when compared by $\chi^{2}$-test $(P>0.1)$. One or more dense-core vesicles of $50 \mathrm{~nm}$ to $100 \mathrm{~nm}$ diameter were seen in about $50 \%$ of the AS terminals of R-type, $4 \%$ of the AS terminals of P-type, $35 \%$ of the AD terminals of R-type, and $25 \%$ of the $A D$ terminals of P-type.

\section{Findings in operated cats}

Eleven cats were allowed to survive for 2 to 7 days after hemicordotomy in the 2 nd cervical cord segment. In all of these cats, changes of degeneration of axon terminals were seen in the caudolateral portions of the MAO and the lateral portions of the DAO ipsilateral to the lesions. Electrondense degenerated axon terminals with discernible active zones were seen most frequently in the cats with a survival period of 3 to 4 days (Plate $4 \mathrm{~A}, 4 \mathrm{~B}$ ). Electron-dense axon terminals and dense bodies engulfed by glial profiles were found in all of 3 cats with a survival period of 2 days, but these were observed most frequently in the cats with a survival period of 5 to 7 days. In a total of 311 electron-dense axon terminals found in the MAO and DAO, 306 were seen on dendritic profiles (Plate $4 \mathrm{~A}$ ) and 5 on

Table 1. The density of AS terminals.

(The number of axosomatic synaptic terminals per $100 \mu \mathrm{m}$ length of the somatic membrane)

\begin{tabular}{lccc} 
& $\begin{array}{c}\text { Number of } \\
\text { cells }\end{array}$ & Range of density & $\begin{array}{c}\text { Mean of density } \\
( \pm \text { S. E. M.) }\end{array}$ \\
\hline Medial accessory olive & 61 & $0-12.0$ & $2.4 \pm 0.34$ \\
Dorsal accessory olive & 45 & $0-8.1$ & $3.0 \pm 0.33$ \\
Principal olive & 41 & $0-8.0$ & $1.7 \pm 0.31$ \\
\hline
\end{tabular}


Table 2. Axon terminals in the inferior olive of the normal cats.

\begin{tabular}{lcrr}
\hline & $\begin{array}{c}\text { Terminals } \\
\text { counted }\end{array}$ & $\begin{array}{c}\text { Terminals with round } \\
\text { synaptic vesicles } \\
( \pm \text { S. E. M.) }\end{array}$ & $\begin{array}{c}\text { Terminals with pleo- } \\
\text { morphic synaptic } \\
\text { vesicles ( } \pm \text { S. E. M. })\end{array}$ \\
\hline Axosomatic terminals & & & \\
$\quad$ Medial accessory olive & 234 & $48(20.5 \pm 2.64 \%)$ & $186(79.5 \pm 2.64 \%)$ \\
$\quad \begin{array}{c}\text { Dorsal accessory olive } \\
\text { Principal olive }\end{array}$ & 232 & $59(25.4 \pm 2.86 \%)$ & $173(74.6 \pm 2.86 \%)$ \\
Axodendritic terminals & 252 & $73(29.0 \pm 2.86 \%)$ & $179(71.0 \pm 2.86 \%)$ \\
$\quad$ Medial accessory olive & 1476 & $859(58.2 \pm 1.28 \%)$ & $617(41.8 \pm 1.28 \%)$ \\
$\quad$ Dorsal accessory olive & 1266 & $775(61.2 \pm 1.32 \%)$ & $491(38.8 \pm 1.37 \%)$ \\
Principal olive & 3355 & $2094(62.4 \pm 0.84 \%)$ & $1261(37.6 \pm 0.84 \%)$ \\
\hline
\end{tabular}

somatic membranes (Plate $4 \mathrm{~B})$; the synaptic active zones were identified in 54 of the former and in 2 of the latter.

Within a DAO area of about $12,500 \mu \mathrm{m}^{2}$ in a cat with a survival period of 4 days, 19 of 355 axon terminals on dendritic profiles were electron-dense $(5.4 \%) ; 1$ electron-dense axon terminal contacting with a somatic profile and 30 dense bodies enveloped by glial profiles were also seen. Within a MAO area of the same size in the same cat, 13 of 273 axon terminals on dendritic profiles were electron-dense $(4.8 \%)$.

Nine cats were allowed to survive for 2 to 7 days after placing lesions unilaterally in the red nuclear regions of the midbrain. Although the extent of the lesions in these cats varied from animal to animal, the features of degeneration of axon terminals within the dorsal lamella of the PO ipsilateral to the lesions were essentially the same as those observed in the MAO and DAO of the hemicordotomized cats (Plate 4C, 4D, 4E). Electron-dense degenerated axon terminals were found most frequently in a cat with a large lesion involving the red nucleus, the medial longitudinal fasciculus, the interstitial nucleus of Cajal, the nucleus of Darkschewitsch and the ventral portions of the central gray. Within a PO area of about $14,000 \mu \mathrm{m}^{2}$ of this cat,
29 of 420 axon terminals in contact with dendritic profiles were electron-dense $(6.9$ $\%)$; 1 electron-dense axon terminal on a somatic profile and 59 dense bodies engulfed by glial profiles were also found. In a total of 172 electron-dense axon terminals found in the PO, 169 were in contact with dendritic profiles and 3 were on somatic profiles; the synaptic active zones were recognized in 26 of the former and in 1 of the latter.

Most of the synaptic vesicles within electron-dense axon terminals observed in the MAO, DAO and PO appeared to be spherical, when they were discernible.

In a hemicordotomized cat and a cat with lesion placed in the mesodiencephalic regions including the red nucleus, the survival period was extended up to the 35 th day after the operation, when all axon terminals of injured neurons were considered to be in detectable stages of degeneration process or to have already disappeared. In these cats, the ratio of the two types of intact axon terminals were calculated and compared with that in the normal cats (Table 3). As regards AS terminals, the ratio of the two types of axon terminals in the operated cats was not different significantly from that in the normal cats $\left(\mathrm{P}>0.1, \chi^{2}\right.$-test). On the other hand, the ratio of AD terminals of R-type to those of P-type was signi- 
Table 3. Axon terminals in the inferior olive of the operated cats with a survival period of 35 days after the operation.

\begin{tabular}{lccr}
\hline & $\begin{array}{c}\text { Terminals } \\
\text { counted }\end{array}$ & $\begin{array}{c}\text { Terminals with round } \\
\text { synaptic vesicles } \\
( \pm \text { S.E. M. })\end{array}$ & $\begin{array}{c}\text { Terminals with pleo- } \\
\text { morphic synaptic } \\
\text { vesicles }( \pm \text { S. E. M.) }\end{array}$ \\
\hline $\begin{array}{c}\text { Axosomatic terminals } \\
\text { Medial accessory olive }\end{array}$ & 148 & $37(25.0 \pm 3.56 \%)$ & $111(75.0 \pm 3.56 \%)$ \\
$\quad \begin{array}{c}\text { Dorsal accessory olive } \\
\text { Principal olive }\end{array}$ & 137 & $40(29.2 \pm 3.88 \%)$ & $97(70.8 \pm 3.88 \%)$ \\
Axodendritic terminals & 162 & $44(27.2 \pm 3.50 \%)$ & $118(72.8 \pm 3.50 \%)$ \\
$\quad$ Medial accessory olive & 1375 & $561(40.8 \pm 1.33 \%)$ & $814(59.2 \pm 1.33 \%)$ \\
$\quad \begin{array}{l}\text { Dorsal accessory olive } \\
\text { Principal olive }\end{array}$ & 811 & $355(43.8 \pm 1.74 \%)$ & $456(56.2 \pm 1.74 \%)$ \\
& 1428 & $463(32.4 \pm 1.24 \%)$ & $965(67.6 \pm 1.24 \%)$ \\
\hline
\end{tabular}

ficantly decreased in the $\mathrm{IO}$ regions on the 35 th day after the operation $(\mathrm{P}<0.01$, $\chi^{2}$-test).

\section{Discussion}

The electron microscopic examination of the IO regions in the present study was carefully limited to the central portions of the olivary nuclear gray, because large reticular neurons existing around the perimeter of the IO have been reported to send their dend rites into the IO domain (Bowman and King, '73; Sotelo et al., '74; Gwyn et al., '77).

Most of the reported ultrastructural features of the cat IO were confirmed in the present study. The frequent occurrence of the intranuclear inclusions in the IO of the cat has been pointed out by Sotelo et al. ('74). According to them, most of the intranuclear inclusions in the IO neurons were of the lattice type (Chandler and Willis, '66), but, in the present study, the inclusions of the rodlet type (Siegesmund et al., '64) were found more frequently than those of the lattice type. In other precerebellar nuclei of the cat, such as the lateral reticular nucleus and the pontine nuclei, the intranuclear inclusions of both types were also seen; the intranuclear inclusions in the neurons of the lateral reticular nucleus of the medulla oblongata in the cat, however, were mostly of the lattice type (unpublished data). Judging from previous data, these intranuclear inclusions did not seem to be pathological entities, although they appeared to tend to increase with age (Feldman and Peters, '72).

$\mathrm{AD}$ terminals of R-type made up about $60 \%$ of the total $\mathrm{AD}$ terminals either in the $\mathrm{IO}$ regions examined, or in the lateral reticular nucleus of the medulla oblongata (Mizuno et al., '75). On the other hand, AS terminals of R-type constituted only $20 \%$ of the total AS terminals in the IO regions examined, and $45 \%$ in the lateral reticular nucleus (Mizuno et al., '75). The density of AS terminals in the IO regions examined ranged from 1.7 to 3.0 in average. Such paucity of the AS terminals appeared to be common in the precerebellar nuclei, such as the lateral reticular nucleus (Mizuno et al., '75) and the pontine nuclei (Holländer et al., '69).

In addition to electron-dense axon terminals, other features of possible degeneration of axon terminals, such as the increase of neurofilaments, the paleness of matrix, the accumulation of glycogen granules and the enlargement of synaptic vesicles, were observed. These features, however, were also seen in the 
normal cat, although only infrequently and in lower grades. In the present study, therefore, these features of axon terminals were not considered as definitely reliable signs of degeneration.

Most of the electron-dense axon terminals found in the present study were in contact with dendritic profiles, and appeared to be of R-type. These degenerated axon terminals, however, constituted only a small fraction of the axon terminals in the IO regions examined; they never exceeded more than $7 \%$ even in the dorsal lamella of the PO in a cat with a large mesencephalic lesion which interrupted all mesodiencephalo-olivary fibers to the dorsal lamella of the IO (Walberg, '56, '74 ; Mabuchi and Kusama, '70; Edwards, '72 ; Loewy and Saper, '78; Saint-Cyr and Courville, '81). Such sparseness of degenerated axon terminals visualized at a particular survival time is possibly attributable to variable time course of degeneration process of damaged neurons (cf. LaMotte, '77). Even in the cats with a survival period of 35 days after the operation, however, many axon terminals remained intact in the IO regions examined; subjective impression was that the number of axon terminals did not seem to be decreased, although the quantitative data suggested a decrease of axon terminals, especially that of R-type terminals.

Extramesodiencephalic fibers terminating in the dorsal lamella in the cat were reported to arise from the striopallidum (Walberg, '56) and the cerebellar nuclei (Graybiel et al., '73; Beitz, '76; Tolbert et al., '76; Berkley and Worden, '78; Mizuno et al., ' $80 \mathrm{~b}$ ). The lateral cerebellar nucleus was confirmed electron microscopically to send AD terminals of R-type to the PO (Mizuno et al., ' $80 \mathrm{~b}$ ), but the existence of fibers from the striopallidum to the IO is questionable (cf. Saint-Cyr and Courville, '81). The dorsal lamella of cat $\mathrm{PO}$ was also reported to receive catechola-minergic fibers sparsely (Sladek and Bowman, '75).

Extraspinal fibers terminating in the spinal fiber-recipient IO regions of the MAO and DAO in the cat were reported to arise from the mesodiencephalic regions (Mabuchi and Kusama, '70; Walberg, '74 ; Loewy and Saper, '78), the cerebellar nuclei (Graybiel et al., '73; Beitz, '76; Tolbert et al., '76; Berkley and Worden, '78), the posterior column nuclei (Ebbesson, '68; Berkley, '75; Boesten and Voogd, '75; Berkley and Hand, '78; Berkley and Worden, '78), the spinal trigeminal nuclei (Berkley and Hand, '78) and the nuclei of the solitary tract (Loewy and Burton, '78). Although cerebral cortical fibers were also reported to terminate in the spinal fiber-recipient IO regions (Walberg, '56), such fibers do not seem to be numerous, if exist (cf. Sousa-Pinto, 69 ; Sousa-Pinto and Brodal, '69; Bishop et al., 76 ; Berkley and Worden, '78). The spinal fiber-recipient IO regions of the cat were further reported to contain numerous indolaminergic (Wiklund et al., '77) and catecholaminergic axon terminals (Sladek and Bowman, '75), arising possibly from lower brain stem regions, especially from the raphe nuclei (Bobillier et al., '76) and the the locus coeruleus.

Other possible sources for the axon terminals which remained intact in the IO regions examined in the operated cats are fibers of intrinsic origin. The presence of axon collaterals of IO neurons terminating within the confines of the IO was suggested electrophysiologically (Armstrong and Harvey, '66 ; Eccles et al., '66 ; Llinás et al., '74) as well as histologically (Ramón y Cajal, '09), while no morphological data have indicated the existence of internuncial neurons within the IO (Ramón y Cajal, '09; Brodal, '40; Scheibel and Scheibel, '55; Bowman and King, '73; King, '76).

Thus, the spinal and rubral fiber- 
recipient IO regions receive many other afferent fibers of various origins. Axon terminals of the spino-olivary fibers in the MAO and DAO as well as those of the mesodiencephalo-olivary fibers in the dorsal lamella of the PO are, at least chiefly, of R-type and terminate mainly on dendrites of IO neurons.

\section{Acknowledgements}

The photographic work of Mr. Akira Uesugi and the support of the Niwa Medical Research Foundation are gratefully acknowledged. This work has been supported in part by Grant-in-Aid for Scientific Research and Grant-in-Aid for Special Project Research from the Ministry of Education, Science and Culture of Japan.

\section{References}

1) Alksne, J. F., Blackstad, Th. W., Walberg, F. and White, L.E., Jr.: Electron microscopy of axon degeneration: a valuable tool in experimental neuroanatomy. Ergeb. Anat. Entwickl.Gesch., 39: 1-32, 1966.

2) Armstrong, D. M.: Functional significance of connections of the inferior olive. Physiol. Rev., 54 : 358-417, 1974.

3) Armstrong, D.M. and Harvey, R. J. : Responses in the inferior olive to stimulation of the cerebellar and cerebral cortices in the cat. J. Physiol. (Lond.), 187 : 553-574, 1966.

4) Beitz, A.J.: The topographical organization of the olivo-dentate and dentateolivary pathways in the cat. Brain Res., 115: 311-317, 1976.

5) Berkley, K. J.: Different targets of different neurons in nucleus gracilis of the cat. J. comp. Neurol., 163 : 285-303, 1975.

6) Berkley, K. J. and Hand, P. J. : Projections to the inferior olive of the cat. II. Comparison of input from the gracile, cuneate and the spinal trigeminal nuclei.
J. comp. Neurol., 180 : 253-264, 1978.

7) Berkley, K. J. and Worden, I. G.: Projections to the inferior olive of the cat. I. Comparisons of input from the dorsal column nuclei, the lateral cervical nucleus, the spino-olivary pathways, the cerebral cortex and the cerebellum. J. comp. Neurol., 180 : 237-252, 1978.

8) Bishop, G. A., McCrea, R.A. and Kitai, S.T.: A horseradish peroxidase study of the cortico-olivary projection in the cat. Brain Res., 116: 306-311, 1976.

9) Bobillier, P., Seguin, S., Petitjean, F., Salvert, D., Touret, M. and Jouvet, M.: The raphe nuclei of the cat brain stem : a topographical atlas of their efferent projections as revealed by autoradiography. Brain Res., 113: 449-486, 1976.

10) Boesten, A. J. P. and Voogd, J.: Projections of the dorsal column nuclei and the spinal cord on the inferior olive in the cat. J. comp. Neurol., 161: 215-238, 1975.

11) Bowman, M.H. and King, J.S.: The conformation, cytology and synaptology of the opossum inferior olivary nucleus. J. comp. Neurol., 148 : 491-524, 1973.

12) Brodal, A.: Experimentelle Untersuchungen über die Olivo-cerebellare Lokalisation. Z. ges. Neurol. Psychiat., 169 : 1-153, 1940.

13) Brodal, A., Walberg, F. and Blackstad, Th. W.: Termination of spinal afferents to inferior olive in cats. J. Neurophysiol., 13: 431-454, 1950.

14) Chandler, R.L. and Willis, R.: An intranuclear fibrillar lattice in neurons. J. Cell Sci., 1 : 283-286, 1966.

15) Courville, J., Montigny, C. de, and Lamarre, Y. (Eds.) : The Inferior Olivary Nucleus: Anatomy and Physiology. Raven Press, New York, 1980.

16) Ebbesson, S. O.E.: A connection between the dorsal column nuclei and the dorsal accessory olive. Brain Res., 8: 393-397, 1968.

17) Eccles, J.C., Llinás, R. and Sasaki, K.: The excitatory synaptic action of climbingfibres on the Purkinje cells of the cerebellum. J. Physiol. (Lond.), 182: 268296, 1966. 
18) Edwards, S. B.: The ascending and descending projections of the red nucleus in the cat: an experimental study using an autoradiographic tracing method. Brain Res., 48 : 45-63, 1972.

19) Feldman, M. L. and Peters, A.: Intranuclear rods and sheets in rat cochlear nucleus. J. Neurocytol., 1 : 109-127, 1972.

20) Graybiel, A. M., Nauta, H. J. W., Lasek, R. J. and Nauta, W. J.H.: A cerebelloolivary pathway in the cat: an experimental study using autoradiographic tracing techniques. Brain Res., 58 : 205211, 1973.

21) Gwyn, D. G., Nicholson, G.P. and Flumerfelt, B.A.: The inferior olivary nucleus of the rat: a light and electron microscopic study. J. comp. Neurol., 174 : 489-520, 1977.

22) Holländer, H., Brodal, P. and Walberg, F.: Electronmicroscopic observations on the structure of the pontine nuclei and the mode of termination of the corticopontine fibers. An experimental study in the cat. Exp. Brain Res., 7: 95-110, 1969.

23) King, J.S.: The synaptic cluster (glomerulus) in the inferior olivary nucleus. J. comp. Neurol., $165: 387-400$, 1976.

24) King, J.S., Andrezik, J. A., Falls, W.M. and Martin, G.F.: The synaptic organization of the cerebello-olivary circuit. Exp. Brain Res., 26 : 159-170, 1976.

25) King, J.S., Bowman, M. H. and Martin, G.F.: The direct spinal area of the inferior olivary nucleus: an electron microscopic study. Exp. Brain Res., 22 : 13-24, 1975.

26) King, J. S., Hamos, J. E. and Maley, B. E. : The synaptic terminations of certain midbrain-olivary fibers in the opossum. J. comp. Neurol., 182: 185-200, 1978.

27) LaMotte, C.: Distribution of the tract of Lissauer and the dorsal root fibers in the primate spinal cord. J. comp. Neurol., 172: 529-561, 1977.

28) Llinás, R., Baker, R. and Sotelo, C.: Electrotonic coupling between neurons in cat inferior olive. J. Neurophysiol., 37 : 560-571, 1974.
29) Loewy, A.D. and Burton, H.: Nuclei of the solitary tract: efferent projections to the lower brain stem and spinal cord of the cat. J. comp. Neurol., 181: 421-450, 1978.

30) Loewy, A. D. and Saper, C. B.: EdingerWestphal nucleus: projections to the brain-stem and spinal cord in the cat. Brain Res., 150: 1-27, 1978.

31) Mabuchi, M. and Kusama, T.: Mesodiencephalic projections to the inferior olive and the vestibular and perihypoglossal nuclei. Brain Res., 17: 133-136, 1970.

32) Millonig, G.: A modified procedure for lead staining of thin sections. J. biophy. biochem. Cytol., 11: 736-739, 1961.

33) Mizuno, N.: An experimental study of the spino-olivary fibers in the rabbit and the cat. J. comp. Neurol., 127: 267-292, 1966.

34) Mizuno, N., Konishi, A., Itoh, K., Iwahori, N. and Nakamura, Y. : Identification of axon terminals of the cerebello-olivary fibers in the cat: an electron microscope study using the anterograde horseradish peroxidase method. Neurosci. Lett., 20 : 11-14, 1980b.

35) Mizuno, N., Konishi, A. and Nakamura, Y.: An electron microscope study of synaptic organization in the lateral reticular nucleus of the medulla oblongata in the cat. Brain Res., 94 : 369-381, 1975.

36) Mizuno, N., Konishi, A. and Nakamura, Y.: An electron microscope study of synaptic terminals of the spino-olivary fibers in the cat. Brain Res., 104: 303308, 1976.

37) Mizuno, N., Konishi, A. Nakamura, Y., Nomura, S., Itoh, K. and Sugimoto, T.: Influence of deafferentation on the synaptic organization in the inferior olivary nucleus: a quantitative electron microscopic study in the cat. In: Y. Tsukada and W. Agranoff (Eds.), Neurobiological Basis of Learning and Memory, John Wiley, New York, 1980a, pp. 19-36.

38) Mizuno, N., Nakamura, Y. and Iwahori, N.: An electron microscope study of the dorsal cap of the inferior olive in the rabbit, with special reference to pretecto-olivary fibers. Brain Res., 77 : 
385-395, 1974.

39) Němeček, St. and Wolff, J.: Light and electron microscopic evidence of complex synapses (Glomeruli) in oliva inferior (cat). Experientia, 25: 634-635, 1969.

40) Ramón y Cajal, S.: Histologie du Systéme nerveux de l'homme et des vertébrés, Tome I, A. Maloine, Paris, 1909, pp. 919-933.

41) Rutherford, J.G. and Gwyn, D.G.: Gap junctions in the inferior olivary nucleus of the squirrel monkey, Saimiri sciureus. Brain Res., 128 : 374-378, 1977.

42) Rutherford, J. G. and Gwyn, D. G.: A light and electon microscopic study of the inferior olivary nucleus of the squirrel monkey, Saimiri sciureus. J. comp. Neurol., 189: 127-155, 1980.

43) Saint-Cyr, J.A. and Courville, J.: Sources of descending afferents to the inferior olive from the upper brain stem in the cat as revealed by the retrograde transport of horseradish peroxidase. J. comp. Neurol., 198: 567-581, 1981.

44) Scheibel, M.E. and Scheibel, A.: The inferior olive: a Golgi study. J. comp. Neurol., 102 : 77-132, 1955.

45) Siegesmund, K. A., Dutta, C. R. and Fox, C.A.: The ultrastructure of the intranuclear rodlet in certain nerve cells. J. Anat. (Lond.), 98: 93-97, 1964.

46) Sladek, J. R., Jr. and Bowman, J.P.: The distribution of catecholamines within the inferior olivary complex of the cat and rhesus monkey. J. comp. Neurol., 163 : 203-214, 1975.

47) Sotelo, C., Llinás, R. and Baker, R.: Structural study of inferior olivary nucleus of the cat: morphological correlates of electrotonic coupling. J. Neurophysiol., 37: 541-559, 1974.

48) Sousa-Pinto, A.: Experimental anatomical demonstration of a cortico-olivary projection from area 6 (supplementary motor area?) in the cat. Brain Res., $16: 73-83,1969$.

49) Sousa-Pinto, A. and Brodal, A.: Demon- stration of a somatotopical pattern in the cortico-olivary projection in the cat. Exp. Brain Res., 8: 364-386, 1969.

50) Tolbert, D. L., Massopust, L. C., Murphy, M.G. and Young, P. A. : The anatomical organization of the cerebello-olivary projection in the cat. J. comp. Neurol., 170: 525-544, 1976.

51) Venable, J.H. and Coggeshall, R.: A simplified lead citrate stain for use in electron microscopy. J. Cell Biol., 25 : 407-408, 1965.

52) Walberg, F.: Descending connections to the inferior olive. An experimental study in the cat. J. comp. Neurol., 104 : 77-173, 1956.

53) Walberg, F.: An electron microscopic study of the inferior olive of the cat. J. comp. Neurol., 120: 1-18, 1963.

54) Walberg, F.: The early changes in degenerating boutons and the problem of argyrophilia. Light and electron microscopic observations. J. comp. Neurol., 122 : 113-123, 1964.

55) Walberg, F.: An electron microscopic study of terminal degeneration in the inferior olive of the cat. J. comp. Neurol., 125: 205-222, 1965.

56) Walberg, F.: Elongated vesicles in terminal boutons of the central nervous system, a result of aldehyde fixation. Acta anat, 65 : 224-235, 1966.

57) Walberg, F.: Does silver impregnate normal and degenerating boutons? A study based on light and electron microscopical observations of the inferior olive. Brain Res., 31: 47-65, 1971.

58) Walberg, F.: Descending connections from the mesencephalon to the inferior olive: an experimental study in the cat. Exp. Brain Res., 21 : 145-156, 1974.

59) Wiklund, L., Björklund, A. and Sjölund, B.: The indolaminergic innervation of the inferior olive. I. Convergence with the direct spinal afferents in the areas projecting to the cerebellar anterior lobe. Brain Res., 131: 1-21, 1977. 


\section{PLATES}




\section{Explanation of Figures}

\section{Plate I}

A: an intranuclear inclusion of the lattice type, seen in a MAO neuron. $\times 60,000$

B: an intranuclear inclusion of the rodlet type, seen in a PO neuron. $\times 50,000$

C: The density of axosomatic synapses upon 100 somatic profiles cut through nucleolar plane; 36 profiles were sampled from the MAO, 34 from the DAO, and 30 from the PO. In the ordinate, the density is expressed as number of synapses per $100 \mu \mathrm{m}$ length of the somatic membrane. In the abscissa, the size of each somatic profile is represented by the average of the longest and the shortest diameters through the nucleolus. 


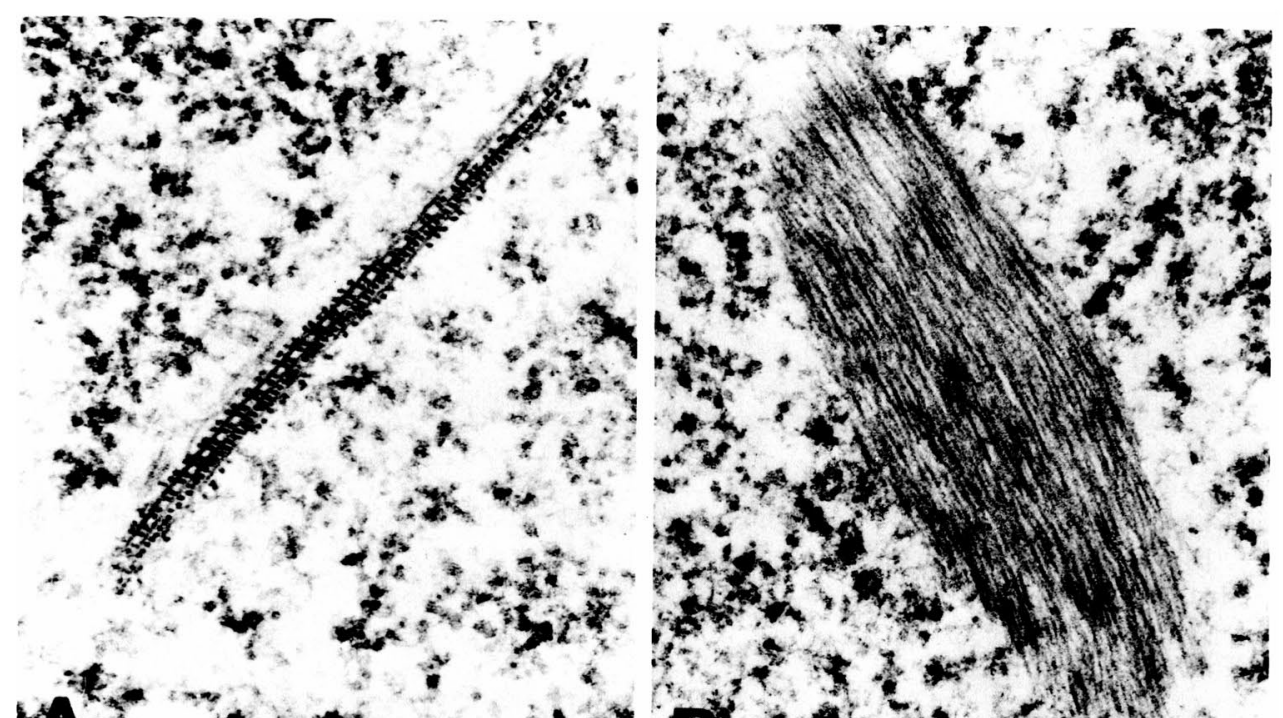

a or festat

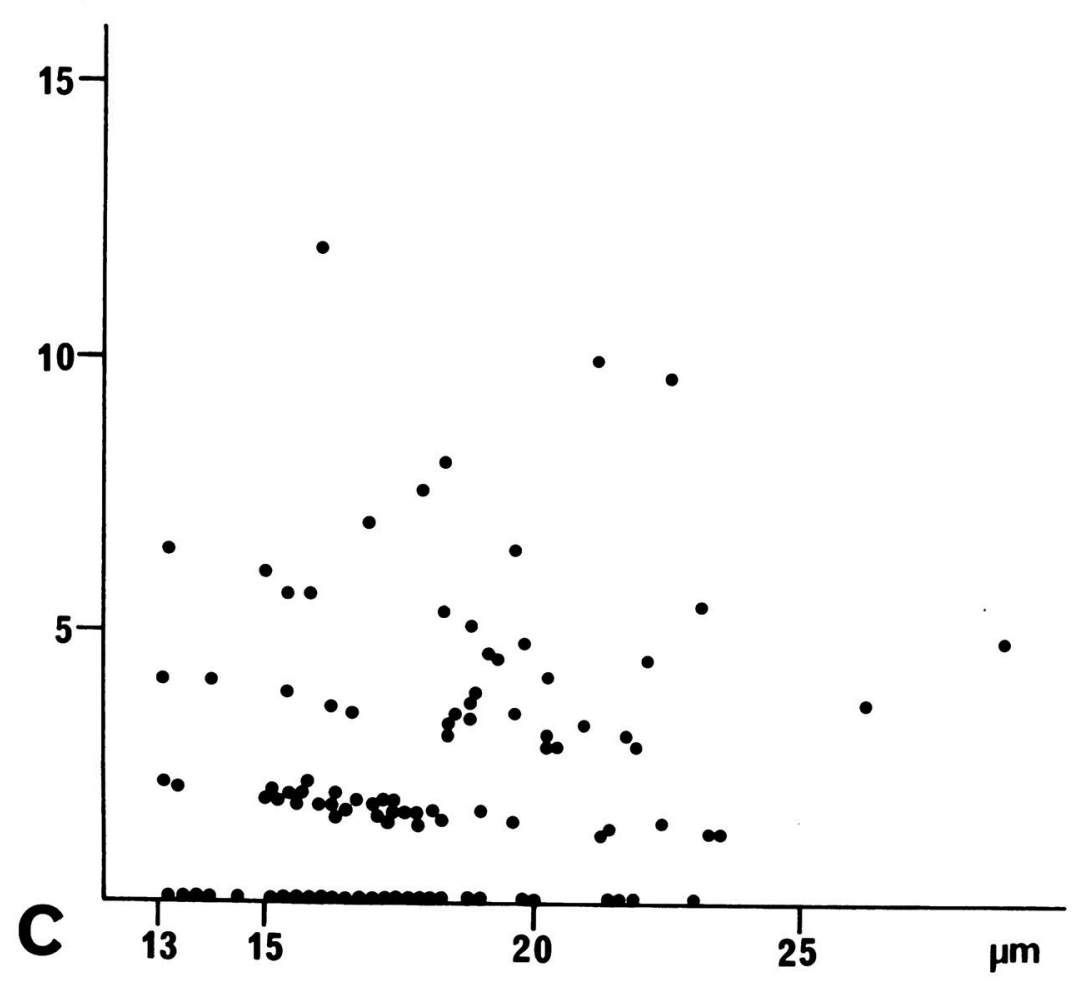

N. Mizuno, et al. 


\section{Plate II}

Casual appositions (small arrows) between a soma and dendrite (A), between neuronal somata (B), and between dendritic profiles (C). A larger arrow in $C$ points to a gap junction between dendrites. A : $\times 10,000$. B: $\times 42,000$. C : $\times 47,000$. 


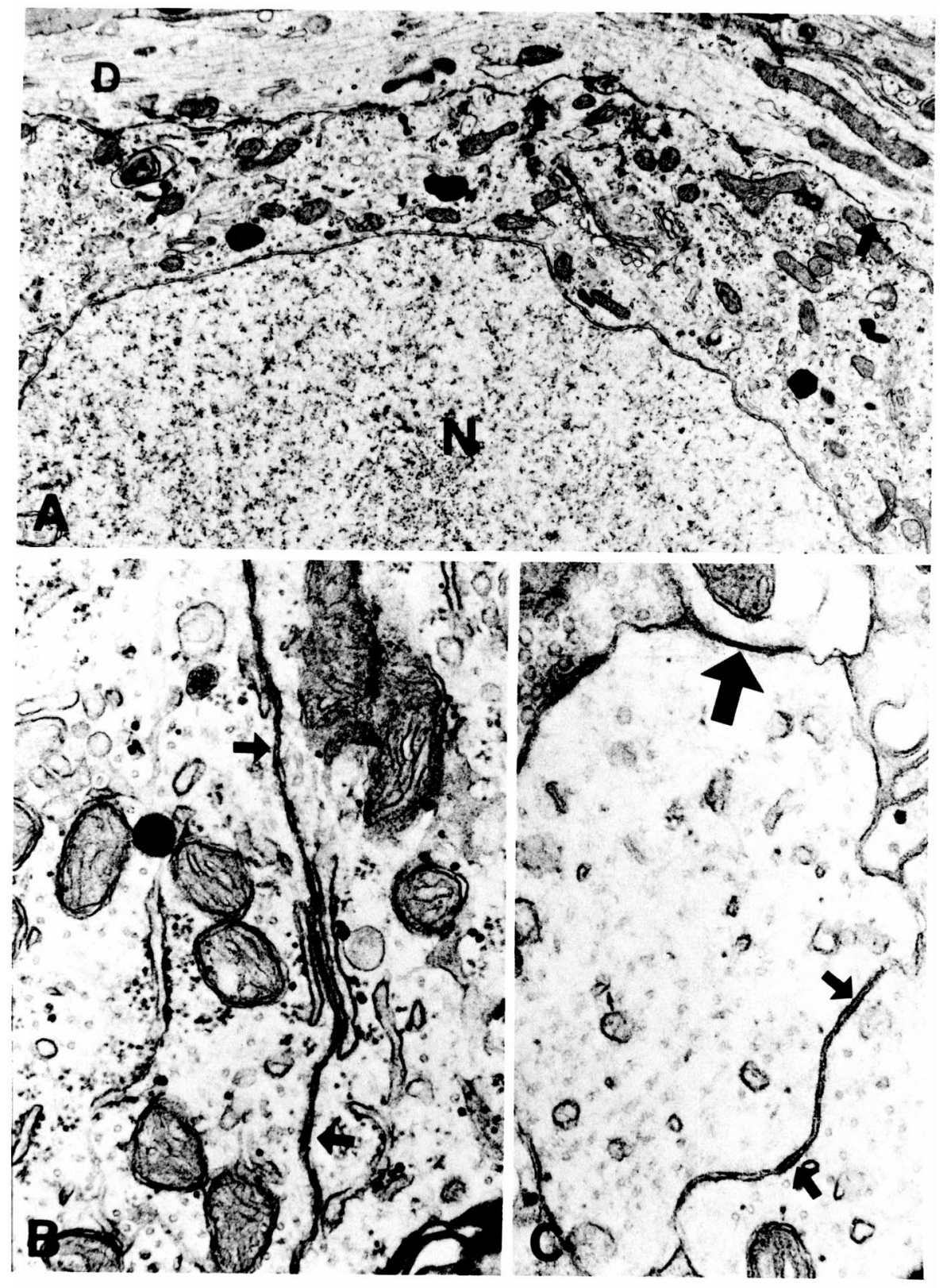




\section{Plate III}

A : Perikaryal myelin (arrows). $\times 10,000$

B: Axosomatic axon terminals of R-type (r) and P-type (p). Arrows with shorter shaft indicate the synaptic active zones, and an arrow with longer shaft points to dense-core vesicles. $\times 20,000$

C: Axodendritic axon terminals of R-type ( $r$ ) and P-type (p). Five axodendritic terminals are arranged around 3 dendritic profiles (d) in a glomerular manner. $\times 20,000$

D : A nodal axon terminal (an arrow) containing pleomorphic synaptic vesicles. $\times 20,000$ 


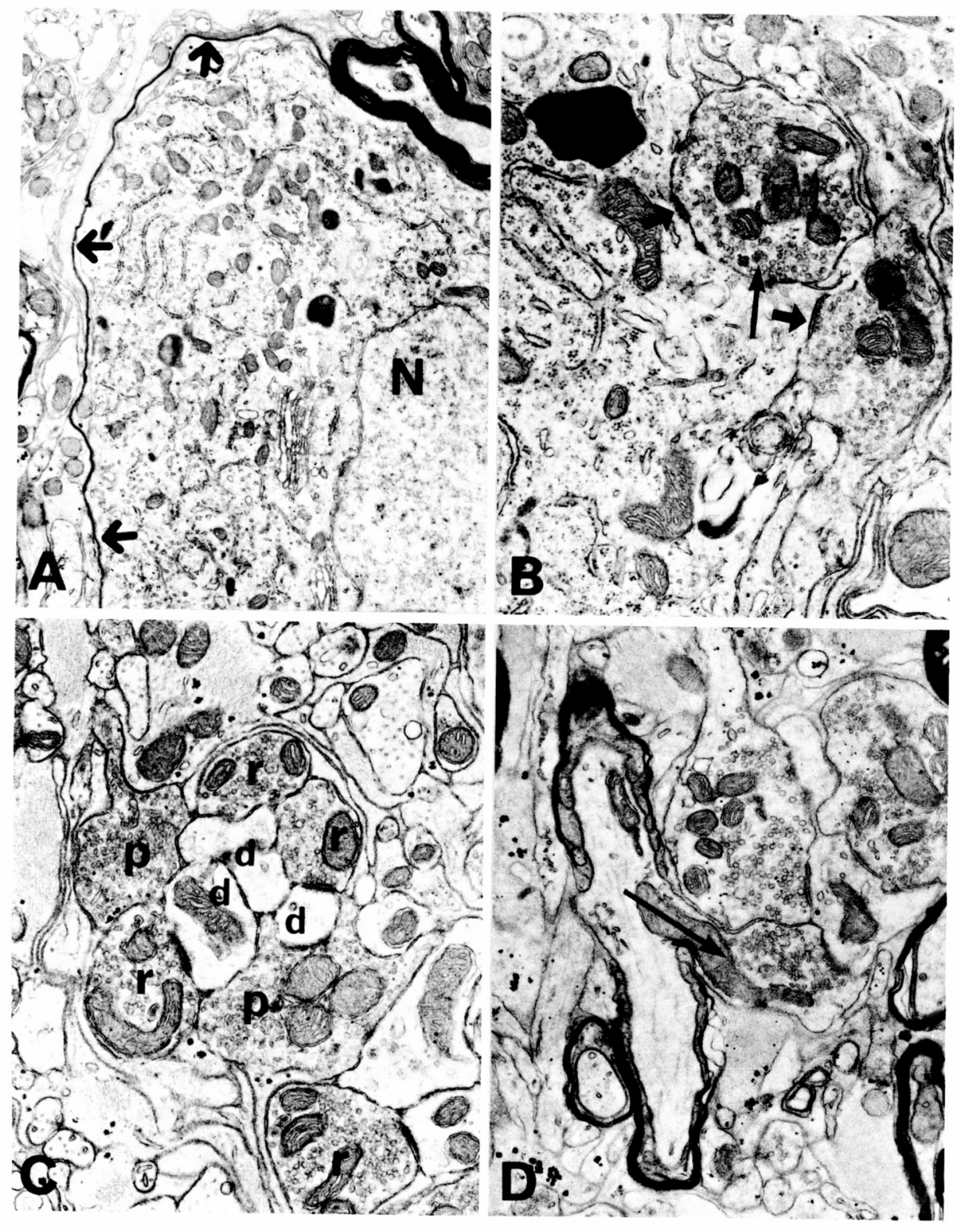




\section{Plate IV}

A : A degenerated axodendritic terminal, seen in the MAO of a hemicordotomized cat with a survival period of 3 days. Two normal axodendritic terminals containing pleomorphic synaptic vesicles are also seen $(p) . \times 33,000$

B : A degenerated axosomatic terminal, found in the DAO of a hemicordotomized cat with a survival period of 4 days. A normal axodendritic terminal containing pleomorphic synaptic vesicles is also seen $(p) . \times 24,000$

C : A degenerated axon terminal is almost surrounded by a glial profile. This was found in the PO of a cat with a survival period of 2 days after placing a lesion in the red nuclear regions. $\times 22,000$

D : A degenerated axodendritic terminal in the PO of a cat with a survival period of 5 days after placing a lesion in the red nuclear regions. $\times 29,000$

E : A dense body is engulfed by a glial profile. This was seen in the PO of a cat with a survival period of 7 days after placing a lesion in the red nuclear regions. $\times 28,000$ 


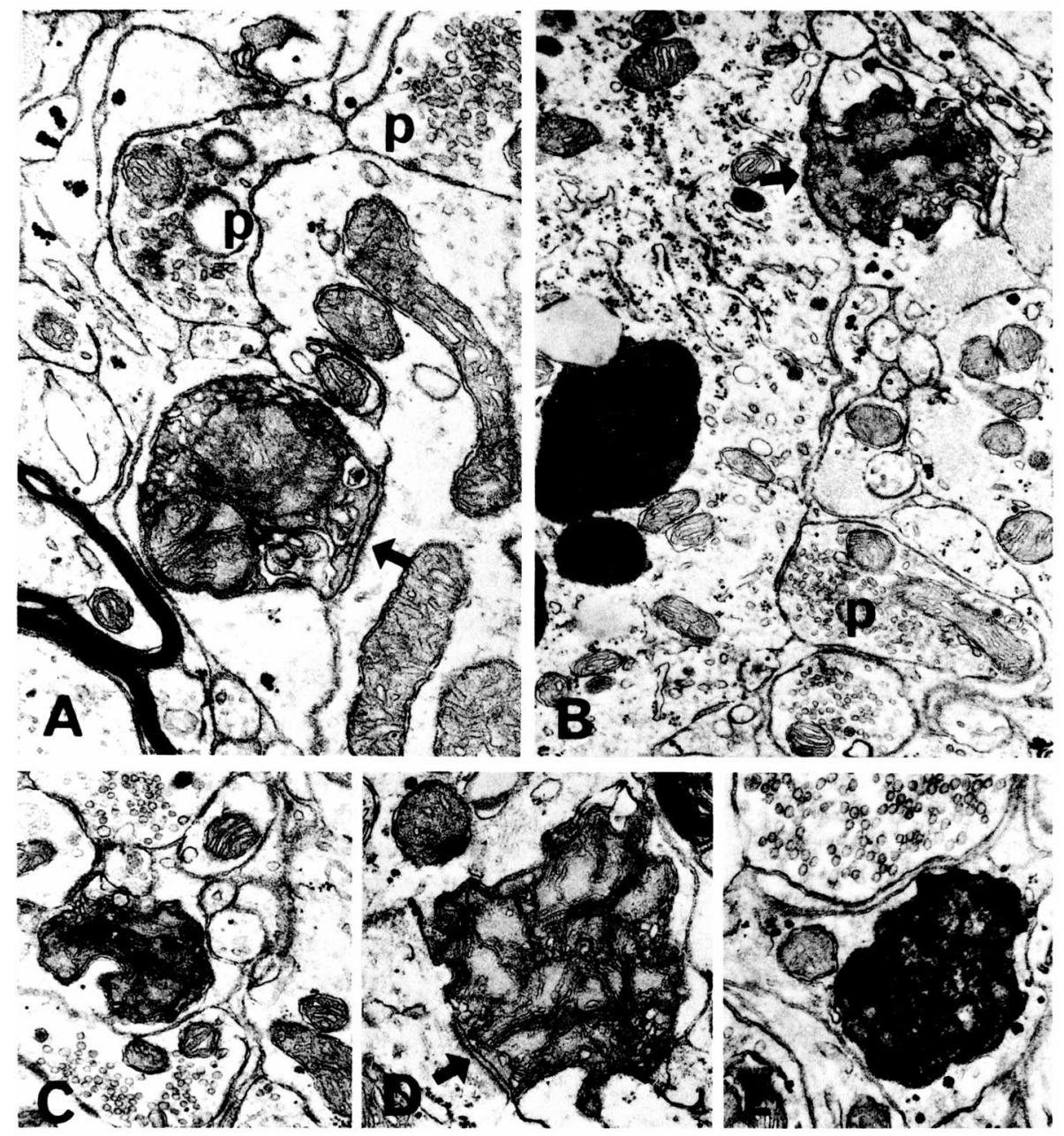

